\title{
Navilouca - uma experiência do encontro entre arte e vida
}

\section{Amanda Costa Ferreira Lucio*}

DOI: 10.11606/issn.2318-8855.v9i1p155-189

Resumo: Este artigo se empenha na observação da relação entre a vida e a arte presente nas páginas do Almanaque Navilouca, organizado pelos poetas Torquato Neto e Waly Salomão, lançado em único volume em 1974. Neste estudo, será investigado como o Almanaque materializou um discurso que dialoga com a proposta de deslocamento da forma e sensibilidade da arte brasileira pós-1968, produzindo uma transmutação das experiências entre arte e realidade. Esta atitude promoveu o recurso da invenção artística, rompendo com os formalismos, inserindo o corpo e comportamento como dimensões políticas e culturais que fomentaram um novo parâmetro para o processo criativo.

Palavras-chaves: Contracultura; Ditadura militar; Navilouca; Revistas de invenção; Torquato Neto;

\footnotetext{
* Graduanda em História pela Universidade Federal de São Paulo. Este artigo é o desdobramento da pesquisa de Iniciação Científica com auxílio do CNPq iniciada em 2018 intitulada "A formação do circuito marginal no Brasil engendrado no Almanaque Navilouca (1974)" sob orientação da Profa. Dra. Maria Rita de Almeida Toledo. E-mail para contato: acflucio@unifesp.br.
} 
Amanda Costa Ferreira Lucio

\title{
Por uma "arte" de invenção
}

\begin{abstract}
Compreenda: analise, transe por cima. Não existe nenhuma "grande dica", isso é romance histórico com personagens histéricos rodando em torno de situações passadas. Não requente coisa alguma, veja de novo, faça outra vez, invente a diferença. Não tem mistério: se não tem forma nova não tem nada de novo. E nada anda. Quem espera grandes dicas não sabe sequer o que fazer com elas caso elas se pintassem, vale de quê? Podes crer. (TORQUATO NETO, 1973, p. 47. grifo nosso)
\end{abstract}

Nessa epígrafe, é possível verificar o modo que Torquato Neto, poeta piauiense residente no Rio de Janeiro, reflete sobre as atividades culturais durante o início da década de 70. Na ocasião, houve um recrudescimento da censura com a decretação do Al-5 (dezembro de 1968). Sufocou-se imediatamente o meio artístico, tal qual estava organizado. Esse fechamento, contraditoriamente, provocou o acirramento das discussões sobre a organização de novos espaços de atuação, padrões, suportes e formas da arte, promovendo a reflexão sobre novas possibilidades de reconfiguração do campo cultural. As potencialidades dessa reconfiguração artística estavam imbricadas nos debates iniciados ainda nos anos 50, em que se buscava o desenvolvimento da atualização da arte brasileira, bem como se ensaiava uma iniciativa para estruturar um "sistema de arte" no Brasil (DUARTE, 2005, p. 135) acompanhando as questões recorrentes nos EUA e Europa.

Na década de 70 - atravessando as tensões políticas e sociais da ditadura estes debates se amplificam e adquirem novas nuances. Antes do fechamento total da ditadura, havia a predominância de uma lógica dualista entre esquerda e direita. Promoveu-se, então, uma arte objetiva que transformasse a realidade institucional, representada nas formas engajadas da esquerda, produzidas sob a pedagogia do Centro Popular de Cultura (CPC) da União Nacional dos Estudantes (UNE); ou nas 


\section{artigos}

\section{Navilouca - uma experiência do encontro entre arte e vida}

formas de um nacionalismo autoritário promovido pelos militares. Como reação à asfixia da arte engajada da esquerda - e nas táticas de oposição à arte oficial mobilizou-se um meio de "sobrevivência intelectual"

fomentado por cineastas, artistas plásticos, compositores, músicos, jornalistas e escritores criaram um espaço em que regras, cânones ou respeito às tradições nacionais foram abolidos em prol de uma maior liberdade de ação e de opinião. O "cinema marginal", "imprensa marginal" e "poesia marginal" configuraram-se como os únicos espaços onde um tipo específico de produção e reflexão cultural pôde ser feito. (COELHO, 2010, p. 200)

É em meio a este espaço situado à margem da cultura oficial que se apresentou, produziu e distribuiu uma diversidade de projetos empenhados na diluição do automatismo da arte. Tal iniciativa explorava a invenção e a subjetividade por meio das diversas experiências como um campo indicativo de uma nova informação cultural. Esta movimentação pode ser examinada mediante a proposta do Almanaque Navilouca: emergindo como um projeto cultural materializado na forma impressa.

É possível compreender os objetivos do Almanaque através da concepção de um de seus já mencionados autores e organizadores, Torquato Neto, que desafiava a ação artística, indicando que havia "espaço à bessa e só você sabe o que pode fazer do seu. Antes, ocupe. Depois se vire." (TORQUATO NETO, 1973, p. 35). Ao indicar a necessidade de apropriar-se dos espaços culturais, dialogando com a prática de utilizar revistas para promover ideias - percurso semelhante aos movimentos de vanguarda da virada do século XIX para o XX - a Navilouca se apropriou da natureza destas revistas porque permitia a criação de um ambiente estético amplo, no qual os novos desenvolvimentos da literatura e das artes visuais poderiam se articular para gerar uma atitude, um complexo gráfico e tipográfico distinto (BRADBURY; MCFARLANE, 1989, p. 163). 


\section{artigos}

\section{Amanda Costa Ferreira Lucio}

Em parceria, Torquato Neto e Waly Sailormoon (pseudônimo de Waly Salomão) organizaram o Almanaque Navilouca, em 1972, cujo lançamento ocorreu apenas em 1974 devido à ausência de investimento financeiro no projeto e sobretudo às complicações relacionadas ao suicídio de Torquato em novembro de 1972. Editada pela Gernasa, no Rio de Janeiro, a publicação em "primeiro volume único" foi intencional, como relatou Torquato Neto em uma correspondência a Hélio Oiticica:

A publicação funcionará em número único, primeiro e único, como o rei momo. A ideia é essa, se pintar outra, pintará com outro nome, outra transação, outra coisa bem diferente. [...] funcionará como uma espécie de antologia, almanaque, revista indefinida, qualquer coisa assim. (NETO, 1972 apud. MORICONI, 2017, p. 194)

Como idealizador do Almanaque, Torquato pensava a imprensa como um ambiente de atuação a ser manipulado para veicular conhecimento e informação. Contribuições anteriormente do autor contavam com reflexões sobre a cultura em jornais como Última Hora (na coluna Geleia Geral), coluna Música Popular no Jornal dos Sports e o contracultural Flor do Mal, junto a Luiz Carlos Maciel, envolvendo-se intensamente com os debates culturais de sua época.

Para viabilizar a publicação de Navilouca, foi necessário o apoio de Caetano Veloso que intermediou o contato entre Waly Salomão e André Midani - executivo da gravadora Polygram - que patrocinou financeiramente o projeto (KHOURI, 2004, p. 21). O impresso foi distribuído como brinde pela gravadora, além de ser vendido em livrarias. A estratégia de distribuição do impresso, adotada pelos seus produtores, buscou diferenciá-lo, considerando que o circuito mais comum da venda de almanaques - impresso de consumo imediato e efêmero - era o das bancas de revista; enquanto a comercialização em livrarias sobrelevava seu caráter exclusivo. Esse deslocamento da distribuição do impresso se, de um lado, valorizava e legitimava o conteúdo de sua mensagem, igualando-o aos livros; de outro, a forma 


\section{artigos}

\section{Navilouca - uma experiência do encontro entre arte e vida}

almanaque colocava em evidência a eleição do provisório, a arte e a vida do horizonte do provável, a renúncia e o repúdio do eterno por parte de uma geração que cresceu à sombra do apocalipse (LEMINSKI, 1989, p. 102).

A distribuição do material pela gravadora indica uma ligação entre o mercado fonográfico e o editorial, assistida na relação que foi construída no Tropicalismo pelos organizadores do impresso e músicos envolvidos: uma parceria ocorrida na elaboração de composições ${ }^{1}$ assinadas por Caetano, Waly, Gilberto Gil e Torquato. É neste tecido de relações que se mesclam diferentes nuances de comportamento e posturas - impelidas pelo desejo de expressar a arte por outros referenciais. $O$ Tropicalismo emergiu como um dos signos desta articulação, posto que os seus espetáculos musicais eram produzidos como performances teatrais. A dinâmica das apresentações desafiava os limites das composições artísticas anteriores, assim como corroborava o delineamento de um espaço que também não convergia com a "cultura e a civilização" vigentes.

No bojo deste debate, a contracultura ou "nova sensibilidade", designada assim por Luiz Carlos Maciel, adotou uma conduta semelhante ao movimentar-se na contramão da sociedade tecnocrática em desenvolvimento, buscando uma libertação dos sentidos e absorção total do vivido, uma vez que a revolução cultural

está em marcha, dizem uns e outros. É verdade. Até em seus recuos, ela não apenas propõe a mudança: ela muda, aqui e agora, através de uma dialética que ninguém definiu. Seu método é a vigência provisória da moda. Através do efêmero ela finca suas raízes. Seu estilo é o improviso incoerente do músico free jazz. Não: ela não deseja destruir tudo para começar de novo. Prefere assumir sua tarefa montada sobre os ombros da tradição, sem compromisso,

\footnotetext{
1 Composições como Louvação (1966), Zabelê (1967), Minha Senhora (1967), Deus Vos Salve Esta Casa Santa (1968), Domingou (1968), Marginália II (1968), Geleia Geral (1968), Mamãe Coragem (1968), Ai de Mim, Copacabana (1968) e A Coisa Mais Linda Que Existe (1969) são resultados da parceria entre Torquato Neto e Waly Salomão com Caetano Veloso e Gilberto Gil.
} 


\section{artigos}

\section{Amanda Costa Ferreira Lucio}

colhendo dessa tradição suas forças desprezadas: o êxtase, o sonho, o ritmo, a cor, o riso, a paz e todos os presentes que o nosso Deus criador oferece aos sentidos humanos para a sua fugaz fruição nesta Terra. (MACIEL, 1973 apud. FAVARETTO, 2019, p. 40)

A incorporação destas condutas no campo cultural e social trouxeram novas bandeiras a serem erguidas pela juventude e estimulou a ênfase das ações, comportamentos e novos sujeitos sociais em suas manifestações. Nesse processo, as práticas sociais adotadas trouxeram para a centralidade o indivíduo como vetor de novas concepções, símbolo da ascensão da revolução cultural ${ }^{2}$ que emergiu na Europa e nos EUA e, com contornos próprios, chegou ao Brasil. Portanto, é fundamental observar como os efeitos desta conjuntura marcaram a elaboração do impresso, no qual, a intersecção destas ideias permite estabelecer alguns parâmetros para entender a produção da Navilouca como produto cultural deste momento.

\section{O almanaque dos aqualoucos}

Conforme Leminski (1989, p. 99), “os maiores poetas (escritos) dos anos 70 não são gente. São revistas". Deste modo, o Almanaque emergiu como um documento/monumento que condensou ideias de diversos indivíduos; e, ao mesmo tempo, pode ser considerado como fruto da exploração de seus repertórios artísticos que se desdobraram posteriormente em diversos projetos, sendo uma prática adotada em outros impressos alternativos da vertente artística como Almanaque Biotônico Vitalidade, Código, Artéria, Polem etc.

\footnotetext{
2 A "revolução cultural" é um termo formulado por Eric Hobsbawm para descrever as manifestações culturais e sociais encabeçadas pela juventude do final da década de 60 , representadas pelo movimento hippie, trazendo propostas de liberação sexual, vida em comunidade, desapego ao consumismo, ecologia, veganismo, misticismo oriental e expansão da mente por uso de substâncias psicodélicas e da psicanálise com o objetivo de fomentar um novo estilo de vida, opondo-se à sociedade tecnocrática em ascensão. Ver em: (HOBSBAWM, 2017. p. 314-336). Esta postura de recusa à cultura moderna está imbricada a uma proposta contracultural de reinterpretar a realidade através do exercício da liberdade. No Brasil, Luiz Carlos Maciel foi o principal divulgador dessas ideias.
} 


\section{artigos}

\section{Navilouca - uma experiência do encontro entre arte e vida}

Alguns aspectos visuais da Navilouca permitem observar o modo inventivo de sua composição em relação à forma de outros impressos do mesmo período. Organizado em tamanho tabloide $(27 \times 36 \mathrm{~cm})$, com projeto gráfico elaborado por Luciano Figueiredo e Oscar Ramos - artistas renomados por montagens cenográficas e de artes plásticas. O layout, estruturado por Ana Araújo - possuía uma elaboração de alto nível em relação a outros impressos da década como o Verbo Encantado, Beijo e o Flor do Mal. O Almanaque foi impresso em cores, diferente de alguns de seus contemporâneos - produzidos, geralmente, em preto e branco e de forma manual (como o Flor do Mal).

A Navilouca também pode ser associada ao jornal Verbo Encantado, que circulou no mesmo período em Salvador, sob a influência de Caetano Veloso e Gilberto Gil. Ambos se caracterizavam como impressos que privilegiavam o artesanal, produções que mesmo possuindo editor fossem individuais e totalmente livres, e tinham como horizonte a liberdade de criação (KUCINSKI, 2003, p.93). Entretanto, a estrutura de Navilouca demonstra que os seus editores estavam empreendendo um projeto cultural diferente, sobretudo se forem observadas as práticas e usos que constituíram a sua forma. Como já mencionado, havia um empenho de Torquato Neto na ruptura com os padrões estéticos vigentes. Para tanto, o Almanaque caracterizou-se como espaço de invenção e experimentação. Torquato Neto, em carta também destinada a Hélio Oiticica, definia seu impresso: "Será qualquer coisa de definitivamente novo, forte e rigoroso. Um escândalo, dada às condições existentes" (NETO, 1972 apud. MORICONI, 2017, p. 197).

Na capa do Almanaque, o título é destacado em grandes letras amarelas está inscrito sobre um fundo vermelho, estampado junto às extravagantes fotografias coloridas dos colaboradores. As fotos foram distribuídas de forma aleatória em sua 


\section{artigos}

\section{Amanda Costa Ferreira Lucio}

apresentação. Essas fotos parecem pertencer ao acervo pessoal das pessoas nelas representadas. Esta observação pode ser constatada por meio do pedido que Torquato faz a Oiticica: que envie "um slide seu, foto sua, carinha do boneco para a capa que vai ser uma espécie de mosaico com fotos de todos nós, fotos bem loucas, você imagina e sabe como que é - mande logo, o mais rápido possível junto com as matérias" (NETO, 1972 apud. MORICONI, 2017, p. 194).

Convém observar que essa correspondência também esclarece outro elemento importante para a análise da elaboração do Almanaque: indica a existência de uma relação de proximidade entre os envolvidos. Essa proximidade permite compreender o impresso como um produto da construção de estruturas de sociabilidade, desenvolvidas nos âmbitos afetivos e ideológicos, nas quais a atividade e o comportamento dos intelectuais envolvidos apresentam traços específicos (SIRINELLI, 2003, p. 252).

Portanto, de acordo com Sirinelli (2003), o reconhecimento dos elementos formadores da identidade do grupo produtor pode ser observado nas escolhas dos dispositivos editoriais que caracterizaram o impresso e materializaram as perspectivas de seus produtores. Esse reconhecimento permite examinar o impresso como espaço cultural no qual atuaram os artistas envolvidos, bem como também permite capturar a situação na qual as ideias engendradas, foram materializadas e veiculadas no projeto artístico presente em Navilouca. 


\section{artigos}

\section{Navilouca - uma experiência do encontro entre arte e vida}

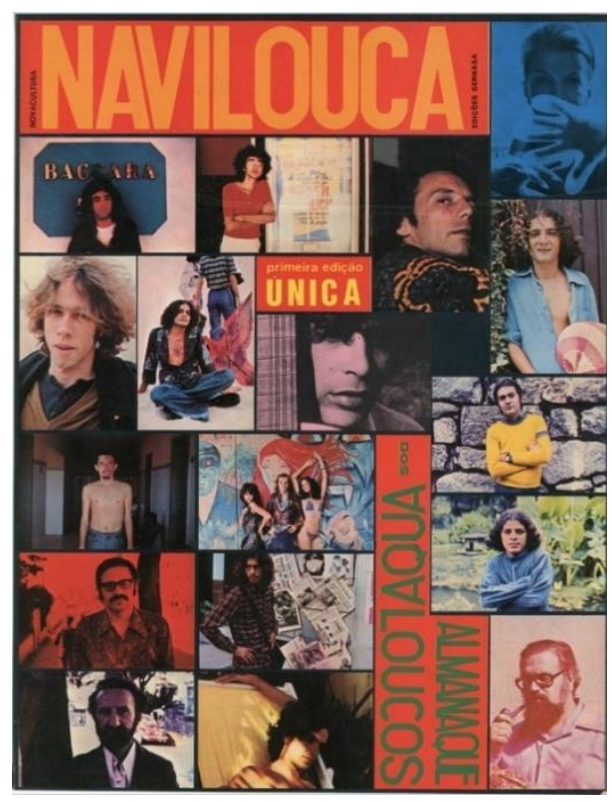

Imagem 1: 'Capa', Navilouca, 1974. Fonte: Torquato Neto, 2018.

No lado esquerdo do título, a palavra "novacultura" pode ser entendida como indício do lugar em que a proposta do Almanaque deveria ser apreciada. Pode também sinalizar as posições e as posturas adotadas por Torquato Neto e Waly Salomão relacionadas ao campo cultural, induzindo a uma nova forma de sensibilidade artística. No canto inferior direito está escrito o nome da editora. Posicionada no centro, está exposta a periodicidade de produção do Almanaque, enfatizando em maiúsculo a escrita da palavra "única".

O subtítulo "Almanaque dos Aqualoucos", escrito de forma invertida em letras verdes, também sobre o fundo vermelho, é uma referência explicativa ao título do impresso, dado por Waly Salomão, em alusão à Stultifera Navis, a nau que trazia todos os loucos e desgarrados no período da Idade Média (HOLLANDA, 1992, p. 73). A configuração do layout permite traçar considerações para atribuir uma identidade ao impresso, identificada na preocupação com o aspecto visual, reconhecido na sua aparência exótica e psicodélica, mas, também no uso da linguagem da publicidade e dos periódicos ilustrados modernos. 


\section{artigos}

\section{Amanda Costa Ferreira Lucio}

É importante destacar que os almanaques, como gênero de impresso, são compreendidos pela sua função de reunir diversas informações necessárias sobre um determinado tema, sociedade ou poder político (LÜSENBRINK, 2006, p. 197). Nessa direção, o Almanaque Navilouca apropriava-se dessa tradição, transformando-se em uma espécie de antologia, cujo critério seletivo era a concepção artística pertencente ao grupo de seus produtores, na qual se estabelece um diálogo estético entre as publicações contemporâneas assinadas pelo mesmo grupo. Ao reunir as obras de Augusto de Campos, Haroldo de Campos, Lygia Clark, Hélio Oiticica, Waly Salomão, Décio Pignatari, Torquato Neto, Luiz Otávio Pimentel, Ivan Cardoso, Jorge Salomão, Stephen Berg, Oscar Ramos, Luciano Figueiredo, Ivan Cardoso, Duda Machado, Rogério Duarte e Chacal, o Almanaque se engaja na veiculação de diversas formas da arte cujo horizonte era comum - reunir o que estava disperso em um único almanaque.

Naquela ocasião, construía-se um espaço de relacionamento criativo e alianças entre os participantes do impresso, tendo como território o Rio de Janeiro, cidade que comportava, desde o século XIX, uma intensa atividade política e cultural, protagonizando o papel de uma das principais metrópoles brasileiras, cujo ambiente urbano matizou as tensões sociais e o caos da modernidade, permitindo, ao mesmo tempo, um intenso fluxo de pessoas, de ideias e atividades diversas. No entanto, outras cidades - como a metrópole paulista e Salvador - foram referentes do grupo de artistas, seja como contraponto, seja como memória urbana.

Essas cidades, devido ao seu caráter central, fomentaram um ambiente gerador de novas artes, ponto central da comunidade intelectual [...] que, sobretudo, permitiu o acesso às instituições básicas como editoras, bibliotecas, patronos, museus e teatros (BRADBURY, 1989, p. 76), expandindo as fronteiras das experiências e 


\section{artigos}

\section{Navilouca - uma experiência do encontro entre arte e vida}

acesso à cultura. Logo, o intercâmbio de experiências vivenciado na metrópole, permitiu o encontro de Waly e Torquato - que eram oriundos da Bahia e Piauí - com outros artistas das vertentes concretistas paulista e carioca, além de cineastas, poetas e outros artistas.

Enfatizando que não há texto fora do suporte que Ihe permite ser lido e não existe compreensão de um escrito, qualquer que seja, que não dependa das formas pelas quais atinge o leitor (CHARTIER, 1991, n.p.), o impresso é aqui analisado não só em seu conteúdo, mas, em sua forma. Por esta perspectiva, a análise da materialidade do impresso indica qual o projeto cultural que estava sendo proposto, assim como os instrumentos mobilizados para construção de sua configuração. Analisar os instrumentos que compuseram as práticas editoriais adotadas permite problematizar as representações dos organizadores do impresso, assim como as estratégias adotadas para a sua circulação. Nesse sentido, é fundamental analisar: a escolha dos locais de distribuição, organização interna do conteúdo, o discurso empregado e o reconhecimento da fórmula editorial adotada para veicular esta nova expressão artística.

Adentrando na análise, um primeiro ponto que chama a atenção na fórmula editorial adotada é o de que muitos dispositivos de controle e organização da leitura estão ausentes: o espaço do editorial, o sumário/índice e mesmo o número das páginas não fazem parte do impresso. Portanto, não há ordenamento da leitura. Não se explica, por meio do editorial, o que é o impresso e como deve ser lido; não se determina, por meio do sumário/índice o que será lido, ou se apresenta a ordem da leitura, excluindo-se qualquer hierarquia de seus conteúdos. Em Navilouca reforça-se essa falta de ordenamento pela ausência de numeração das páginas, proporcionando ao leitor uma maior liberdade de apreensão do material, já que não há ordem 


\section{artigos}

\section{Amanda Costa Ferreira Lucio}

alguma. A própria forma do códice permite que o leitor acesse qualquer página, sem se preocupar com que vem antes ou depois.

A exclusão destes dispositivos referenciais expressa uma recusa às formas tradicionais de organização do impresso, rompendo com a configuração convencional dos materiais do gênero. O exercício da invenção artística de Navilouca se faz evidente no subjetivo, na medida em que sua composição consistiu em apropriar-se da forma editorial para transformá-la em outra, favorecendo uma leitura mais fluída e desregrada conduzida unicamente pelo leitor.

Ainda no exercício de reapropriação da forma-almanaque, também estão ausentes na organização do impresso as seções que distribuem ou classificam as matérias publicadas. O único dispositivo identificável de distribuição dos conteúdos é o uso das fotografias dos diferentes participantes, legendadas com seus nomes. São essas imagens que separam os conteúdos nas diferentes formas de uso dos espaços das páginas. Contudo, ao mesmo tempo, estão integradas à própria organização da obra nas páginas.

Em relação à autoria das obras publicadas, a atribuição da referência pode ser identificada pelas fotografias - ou em alguns casos, a aparição de obras de alguns autores nos espaços-página de outros. Este aspecto permite a reflexão sobre uma relativa dissolução da autoria, o que transforma o projeto em um objeto comum a todos os participantes, pois a submissão da invenção a um nome está ausente ou ocultada pela forma como a posição dos produtores da arte são referidas nas páginas do Almanaque. Se o nome do autor permite reagrupar um certo número de textos, delimitá-los, deles excluir alguns, opô-los a outros [...] manifestando a ocorrência de um certo conjunto de discurso, e referendando o status desse discurso no interior de 


\section{artigos}

\section{Navilouca - uma experiência do encontro entre arte e vida}

uma sociedade e de uma cultura (FOUCAULT, 2001, p. 277), sua supressão também elimina (nesse caso, novamente) a função classificatória e sistemática do discurso.

Deste modo, o layout revelava previamente ao leitor a adoção de uma linguagem e estruturação despojadas, esparsas, com forte apelo à visualidade e experiências subjetivas. A manipulação destes dispositivos, ou a ausência de muitos deles, permitiu o alargamento da perspectiva de que os rótulos, institucionalizações e formas acadêmicas não são mais elementos determinantes na formação do repertório artístico. É na análise destas representações propostas que o estudo se debruça.

\section{Entrecruzando gerações}

Como já constatado, Navilouca foi um projeto coletivo que materializou a colaboração de diversos sujeitos que atuavam no meio cultural e artístico durante o período de sua elaboração e lançamento. Com efeito, é necessário identificar os meios pelos quais os envolvidos circulavam para compreender de maneira mais precisa qual a intencionalidade dos seus projetos e as influências que exerceram na materialização de Navilouca. Entre os fenômenos culturais daquele momento, o Tropicalismo foi inicialmente um referente importante para o Almanaque, uma vez que havia intenso contato entre os seus organizadores e o grupo baiano tropicalista.

Pode-se dizer que no Tropicalismo também havia um desejo de instaurar um novo sentido para a arte brasileira, redirecionando a questão das tradições culturais pela sua articulação com a cultura pop e difundindo os resultados da fusão através dos meios de comunicação,

evidenciando esta atitude de brincar, mexer e introduzir elementos de resistência e desorganização nos canais legitimados pelo sistema. Assim, o 


\section{artigos}

Amanda Costa Ferreira Lucio

fator da técnica é preservado, mas, simultaneamente subvertido (HOLLANDA, 1992, p. 73).

Esta fusão de elementos culturais filiava-se aos temas propostos pelos movimentos de vanguarda da década de 20 que, na assertiva de Oswald de Andrade, pugnava: "nenhuma fórmula para a contemporânea expressão do mundo. Ver com olhos livres." (ANDRADE, 1924 apud. TELES, 1973, p. 2). Esta perspectiva formulava a composição de um caleidoscópio de referências que se apresenta no Almanaque, sendo observado também através do prisma da intensa convivência e troca de conhecimento entre os envolvidos: a união de gerações distintas que compartilhavam opiniões semelhantes para a elaboração de suas experiências artísticas.

É neste ponto que se revelam, nas páginas do Almanaque, as referências da Poesia Concreta da década de 50: representada em São Paulo pelo grupo Noigandres - composto pelos irmãos Haroldo e Augusto de Campos - em conjunto com Décio Pignatari e a revista Invenção; assim como pelos Neoconcretos cariocas, representados por Hélio Oiticica e Lygia Clark. Esse movimento funcionou como ponto de referência para a elaboração das formas estéticas experimentais e linguagem que permeou o conteúdo do Almanaque. O que remete à associação de diversas linguagens e técnicas, promovendo uma arte de vanguarda, pois, a poesia coloquial que explorava o cotidiano, focada no som das palavras, encontra-se com uma poesia visual, empregando a superfície da página com o apelo visual de ilustrações, imagens e formas. Esse entrecruzamento, se desenvolvia na conjugação da atuação da juventude tropicalista com a prática dos Concretos, de modo a atualizar sua atividade, proporcionando relação de continuidade e renovação.

Em consonância, a relevância da figura de Hélio Oiticica possui posição central no intercâmbio destas ideias entre as duas gerações, sendo estas entendidas aqui 


\section{artigos}

\section{Navilouca - uma experiência do encontro entre arte e vida}

como os Tropicalistas e os Concretos no fomento desta proposta de "invenção". O poeta e artista plástico carioca pertencia à vertente Neoconcreta, que por sua vez, era uma dissidência do grupo Concreto paulista. Essa dissidência tinha como ponto de inflexão novas perspectivas, passando a se debruçar sobre a abertura de novas formas materiais mais fluídas, afastando-se da homogeneização dos referentes e objetos artísticos produzidos pelo grupo paulista (AGUILAR, 2005, p. 128).

Contudo, é preciso enfatizar que os Concretos não determinaram os rumos tomados pela produção do trabalho, destacando-se mais pela inspiração, forma de apadrinhamento e interlocução da reunião dos envolvidos com o Tropicalismo (Caetano Veloso, Gilberto Gil, Torquato Neto, Capinam etc.). A questão dos meios de comunicação de massa parecia ser central para os dois grupos. O Tropicalismo surgiu como um movimento jovem afirmando seu papel dentro da comunicação de massas, utilizando-a como vetor de ruptura e desvio. Para os Concretos, a influência do alcance destes meios possibilitava a modificação nos mecanismos da cena pública e a criação de imagens culturais (AGUILAR, 2005, p. 118). Assim, a atuação do Tropicalismo, ressignificada pela posição dos Concretos, se apresenta como um evento cultural que produz uma atualização de algumas reflexões sobre a arte que já estavam em elaboração desde a década de 50.

Em conformidade com esta perspectiva, está a proposição de uma arte que, pautada pela vanguarda, só poderia ser concebida como antiarte, pois o rompimento com os padrões estabelecidos altera a lógica dos objetos e seu discurso, atribuindo uma nova visão da forma, corroborando a tese de que a cisão da linguagem abre espaço para outras formas de reorganizar o código e a comunicação (PIGNATARI, 1973, p. 169). É na influência deste diálogo entre as duas gerações que está o escopo do Almanaque, no qual, a utilização da arte para explorar as instâncias de uma 


\section{artigos}

Amanda Costa Ferreira Lucio

sociedade em transformação se evidencia na prática adotada de renovar as tradições, enredando novos discursos através dos meios de comunicação de massa.

\section{O experimental experimentado}

A posição adotada pelos idealizadores de Navilouca, Torquato Neto e Waly Sailormoon, foi a de se empenharem em ocupar espaços e assumir a loucura, na medida em que se afastavam dos formalismos da arte e alargavam suas fronteiras. Nessa perspectiva, Hélio Oiticica expõe em seu texto-manifesto "Experimentar o experimental": que os "fios soltos do experimental são energias que brotam para um número aberto de possibilidades, no brasil há fios soltos num campo de possibilidades: por que não explorá-los?" (OITICICA, 1974, p. 35). Isso é um ímpeto de construir espaços, de manifestar o vivido através dos fragmentos dos fios da realidade. Um comportamento que incide na reflexão sobre as diversas dimensões racionalizantes do cotidiano.

Ainda, em "Experimentar o experimental", é discutida a dificuldade de produção de um programa experimental nas obras de artistas brasileiros. Oiticica comenta que "os talentos potenciais individuais são logo diluídos no dia-a-dia competitivo que estanca o experimental"; acrescentando, que "a arte apenas revive o que já existe, enquanto o experimental retoma [...] esses artistas que constroem um pedaço de escultura e chamam de arte não passam de narcisistas... criar não é tarefa dos artistas. Sua tarefa é a de mudar o valor das coisas." (OITICICA, 1974, p. 35-36).

Para Oiticica, havia uma diversidade de trabalhos publicados que estavam orientados por esta lógica. O traço especifico em comum destas produções é iluminado por uma ideia de que as linguagens artísticas - poesia, cinema, fotografia, artes plásticas - precisam ter seus sentidos reorganizados. A antiarte aspira afastar-se 


\section{artigos}

\section{Navilouca - uma experiência do encontro entre arte e vida}

da imagem do intelectual hermético, das formas, instituições e sistema artístico. Este deve assumir uma conduta anticonformista diante dos enquadramentos estéticos e políticos. Deste modo, o "artista" deve pretender superar a ideia de "obra" para engendrar novas formas de participação na sociedade, vivificando o sentido do que seria "artístico" - transformando a vida em um processo criador e criativo.

Nesta direção, observando as possibilidades diversas da realidade, Waly anuncia a necessidade de uma compreensão mais fluída dos processos artísticos. Em um tom de queixa, o autor relata uma insatisfação com a forma de compreensão das suas obras:

Queu não estou disposto a ficar exposto a cabecinhas ávidas quadradas ávidas em reduzir tudo todo esforço grandioso como se fosse expressão de ressentimentos por não se conformar aos seus padrões culturais: meu texto não é só para ser visto numa ordem emocional (grilado ou sem bode, numa "boa" ou numa "ruim", incucado ou desbundado, alegre ou triste, amor ou ódio, etc.) [...] deve ser visto de uma ordem mais impressiva, menos passiva, mais criadora - como experimentação de novas estruturas, novas formas de armação, como modo de composição não-naturalista. Alargamento não ficcional da escritura. (SAILORMOON, 1974, p. 16. grifos nossos).

Pode-se acrescentar que Waly expõe que o "esforço grandioso" - entendido como a elaboração do Almanaque - não é resultado de um sentimento de simples rejeição à cultura oficial e sim um empenho na elaboração de uma nova sensibilidade da arte. Esta convicção é revalidada na matéria que relata o lançamento do seu livro Me segura qu'eu vou dar um troço, no qual, Waly fala da insensibilidade das áreas da cultura brasileira que "não suportam o que existe de tecnicamente desenvolvido, elétrico, moderno no meu trabalho, eles preferem me manter como ingênuo" e prefere pessoas que, "como Rogério Duarte, assumem integralmente a sua loucura, pessoas em constante mutação, assim como eu." (SAILORMOON, 1974, p. 25). Demarcando um posicionamento desinteressado no seu reconhecimento como 


\section{artigos}

\section{Amanda Costa Ferreira Lucio}

intelectual ilustre no território cultural brasileiro, Waly opta pela permanente "transação" de ideias na realização de suas produções.

Por um percurso semelhante, o texto desenvolvido no espaço-página que indica autoria de Décio Pignatari, põe a poesia em um campo experimental, transformando-se em poesia-descoberta, poesia-invenção que vai dizendo a sua descoberta na medida mesma em que a faz (PIGNATARI, 1974, p. 103). O poema intitulado "Pháneron, l" é composto para reproduzir um texto que, de acordo com o próprio autor, foi "absorvido", escrito e refeito ao longo de sua vida, indicado por mapas onde ocorreram os encontros, fotografias pessoais e dos envolvidos naquele processo de absorção.

Pignatari produz uma poesia que se desloca da linguagem comum, rompendo com a sistematização da apreensão da leitura, observada em sua própria construção que estimula a visualidade da palavra, por meio do rompimento da estrutura gramatical e morfológica. O autor não apenas redige a palavra, como é absorvido, tomado por ela, transformando-se em seu objeto. Esta cisão da linguagem permite abertura para novas formas de organização do código e comunicação (PIGNATARI, 1973, p. 169). Esta ideia de solapamento da objetividade proposta pelos autores se desvela na medida em que o local da linearidade é ocupado pela simultaneidade de elementos. Assim,

esta ausência de sistematização procura eliminar resquícios de estilo [...] o estilo implica configurações estéticas, da criação, da recepção; a falta de estilo abre campo para a inclusão do comportamento como móvel da atividade artística, quer isto se materialize em obras ou não. (FAVARETTO, 2019, p. 4748).

Nesta destituição das formas, Augusto de Campos se apropria de forma irônica do soneto, reforçando a ideia da rearticulação das formas como proposta artística. 


\section{artigos}

\section{Navilouca - uma experiência do encontro entre arte e vida}

Em "Soneterapia", por exemplo, o deboche está na utilização do formato do soneto como terapia. No soneto há a lamentação do não reconhecimento de poetas que influenciaram uma reformulação poética como: "drummond perdeu a pedra: é drummundano/ joão cabral entrou pra academia/ custou mas descobriram que caetano/ era o poeta (como eu já dizia)." (CAMPOS, 1974, p. 5). No poema, o autor também manifestou a importância da Poesia Concreta como elemento articulador de uma arte de vanguarda no Brasil. Mesmo sendo rechaçado por uma parcela da intelectualidade, o autor expressa: "o concretismo é frio e desumano/ dizem todos (tirando uma fatia)" além de denunciar o apagamento de alguns poetas em troca de uma provável ascensão ao panteão beletrista, afirmada na continuação "e enquanto nós entramos pelo cano/ os humanos entregam a poesia." (CAMPOS, 1974, p. 5).

Como se observa, a apropriação desta linguagem no Almanaque indica a adoção de um projeto que buscava diluir a apreensão racional da literatura, superando as barreiras que enquadram a poesia - assim como todas as linguagens artísticas - como um objeto a ser interpretado, abstraído pela técnica ou contemplação. As inquietações dos sujeitos, o não ordenamento do discurso, flexibilizam o aspecto homogêneo da produção artística. Deste modo, a "arte", no ponto de vista dos autores, se torna um espaço de invenção que amplia o exercício livre de criar, onde este movimento de descontração está na valorização dos estilos de vida e formas de experiência cultural que questionam as formas sérias e excessivamente racionais, burocráticas, tanto da vida como do pensamento (PEREIRA, 1981, p. 190).

\section{A performance do espontâneo}

Ainda na análise de Navilouca, observa-se que na segunda capa está estampada 


\section{artigos}

\section{Amanda Costa Ferreira Lucio}

uma fotografia da intervenção poética de Waly com "Alfa Alfavela Alfaville", que traz um grupo de jovens na praia segurando grandes letras vermelhas que formam o título da obra. Os integrantes do grupo ostentam cabelos longos, alguns estão sem camisa, descalços e posando de forma despretensiosa. Em meio aos jovens, é possível reconhecer Waly.

Nesta configuração, o autor se coloca como o criador da obra e também participante do que provavelmente alude à condição do desembarque dos integrantes da Navilouca. A foto ambienta um cenário descontraído, com jovens sorridentes frente ao mar e é inserindo no impresso por meio da linguagem fotográfica. No desembarque, se observa a participação do corpo como elemento integrante da obra: uma relação entre o corpo e a arte configurada como uma passagem do real ao imaginário (FAVARETTO, 2019, p. 57).

É neste desenlace da apropriação do corpo e do vivido, colocados em evidência na performance do espontâneo, que se atribui um aspecto político ao comportamento. Este espontâneo é identificado pela atitude assumida pelos jovens que, ao posarem na praia, produziram um discurso que evocava a valorização dos estilos de vida e da liberdade, de não-reprodutibilidade, realçando a importância do acontecimento, da captura do efêmero e da experiência vivida. Esta prática aparece de forma recorrente nas diversas experiências projetadas nos usos das linguagens visuais e literárias de Navilouca, incorporando as experiências dos indivíduos como expansões do campo criativo. Impossíveis de serem assimiladas de forma objetiva, estas estruturas artísticas são reproduzidas nas esferas do cotidiano. 
Navilouca - uma experiência do encontro entre arte e vida

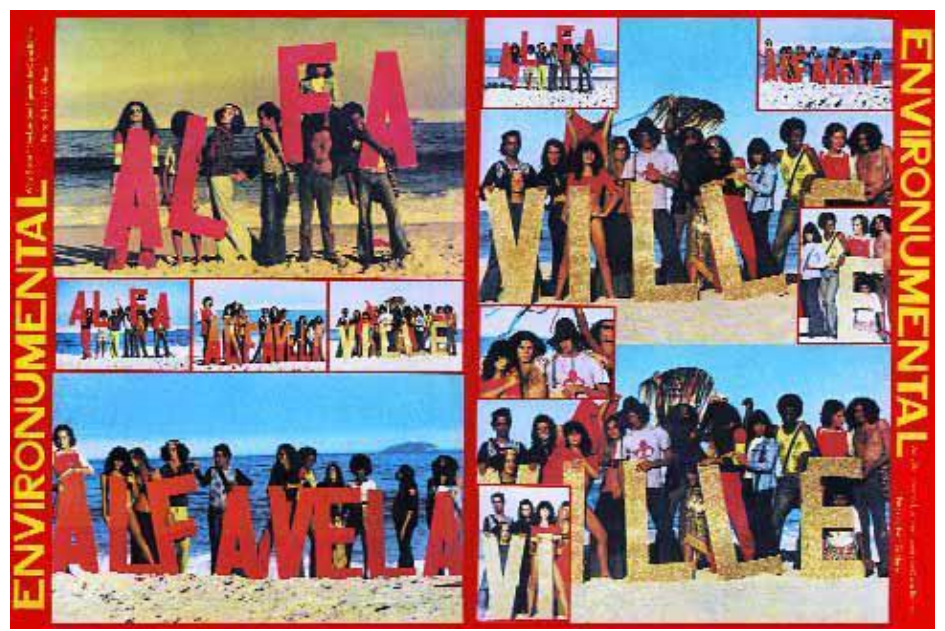

Imagem 2 - 'Alfa Alfavela Alfaville'. Navilouca, 1974. Fonte: PPGAV-UFRJ, 2012.

Esta ênfase na proposição da vida como arte está ancorada numa perspectiva em que a performance do corpo não aparece apenas de forma simbólica, mas carregada de sentido político, ampliado ao comportamento - ilustrado pelo corpo. Esta questão desponta como um aspecto central para a investigação do Almanaque, respaldado no posicionamento artístico que se emprega nas obras. A emergência corporal é tema recorrente das linguagens diversas, assim como a representação do comportamento anárquico, contestador, entendido como

\begin{abstract}
A proposta da arte como vida. Também está aí uma nova figuração da política, numa zona de indistinção entre o que antes era crítica da cultura e agora é crítica imanente da cultura: uma poética do instante e do gesto que desloca os simbolismos da arte em favor dos comportamentos, da vida como manifestação criadora. (FAVARETTO, 2019, p. 198, grifos nossos).
\end{abstract}

A presença do corpo e suas performances são aspectos que manifestam o elemento experimental presente nas produções artísticas deste grupo, uma vez que a performance do corpo é um dos elementos incorporados pelos Neoconcretos em seus projetos. Os Parangolés (1964) ${ }^{3}$, de Hélio Oiticica, são inseridos na Navilouca, por

\footnotetext{
${ }^{3}$ Desenvolvido em 1964, os Parangolés de Hélio Oiticica constituem a elaboração de um conjunto de obras que se debruçaram na experiência de vestir diversas capas, bandeiras, estandartes feitos com tecidos coloridos com inscrições que, segundo Oiticica, promoveriam uma totalidade da vivência da
} 


\section{artigos}

Amanda Costa Ferreira Lucio

uma fotografia em preto e branco de página inteira em que Omar Salomão aparece posando de costas, vestindo a capa n. 24 com o ideograma "escreabuto" inscrito (OITICICA, 1974, p. 40). Essa imagem situa a ênfase do objeto sobre o corpo, introduzido por meio da participação do espectador na obra,

Pois, o vestir já em si se constitui numa totalidade vivencial da obra, pois ao desdobrá-la tendo como núcleo central o seu próprio corpo, o espectador como que já vivencia a transmutação espacial que aí se dá: percebe ele, na sua condição de núcleo estrutural da obra, desdobramento vivencial desse espaço intercorporal. O assistir já conduz o participador para o plano espaciotemporal objetivo da obra, enquanto que, no outro, esse plano é dominado pelo subjetivo-vivencial; há aí a completação da vivência inicial do vestir (OITICICA, 1986, p. 7).

As experiências vividas por meio da participação na obra levariam a uma maior apreensão da mesma, permitindo diversas percepções da criatividade, como também fomentaram a produção de uma arte que não pode ser registrada pelos meios convencionais, já que a sua totalidade é absorvida de maneira corporal. Assim, na arte, houve uma alusão ao subjetivo, se deslocando de uma fruição meramente óptica para um processo no qual o caráter reflexivo se tornava o novo centro de gravidade (DUARTE, 2005, p. 133).

Em consonância com esta iniciativa, no espaço-página que traz trabalhos relacionados a Jorge Salomão, Navilouca remonta a incidência da necessidade de introdução do corpo como expurgo e manifestação das sensações da vida. $\mathrm{Na}$ publicação "Nascer através da dor", a performance improvisada de explosão de som e dança ilustra quatro fotografias em preto e branco em que Jorge Salomão, José Simão

obra, ampliando a apreensão do espectador por meio da abertura do processo de criação. Assim, o criador das obras fomenta a criação das obras junto com o público, distanciando-se da passividade da contemplação. Com os Parangolés, sobretudo, há um deslocamento da função social da arte - a fruição sensorial abre espaço para a desintelectualização da arte que está relacionada com "a derrubada de preconceitos sociais, das barreiras de grupos, classes etc., seria inevitável e essencial na realização desta experiência vital." (OITICICA, 1986, p. 73) 


\section{artigos}

\section{Navilouca - uma experiência do encontro entre arte e vida}

e Zé Português, estão sem camisa, ostentando os cabelos compridos, na captura deste movimento da criação espontânea, no qual, a palavra "espetáculo" se destaca como único elemento colorido ao centro. Um ensejo que é reafirmado no poema escrito abaixo das fotos, no qual se destaca o verso "Eu, dançando, nesses esparsos palcos da vida" (SALOMÃO, 1974, p. 45). O corpo em movimento performático traz à realidade o espetáculo das relações humanas, experimentada na gestualização que imbrica as relações entre arte e vida.

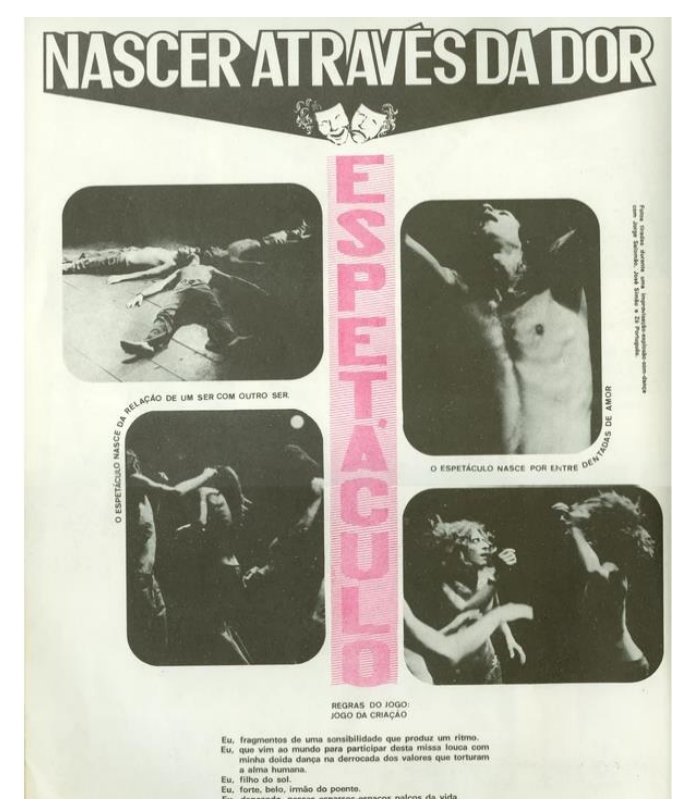

Imagem 3 - 'Nascer através da dor'. Navilouca, 1974. Fonte: Torquato Neto, 2018.

Ainda nesta premissa de inserir o corpo como elemento que atribui um novo sentido para a arte, no espaço-página, que também remete a Jorge Salomão, está exposta uma grande faixa cor de rosa escrito "Estraçalhar as neuras pelas vontades do corpo" (SALOMÃO, 1974, p. 50). Abaixo, estão inseridas duas fotografias em preto e branco: na primeira, há um jovem de cabelos compridos deitado despido na praia; enquanto na segunda, ele traz uma placa onde se lê "O homem é o aperfeiçoamento da sua linguagem". 


\section{artigos}

\section{Amanda Costa Ferreira Lucio}

O que se pode extrair das análises do projeto de Navilouca é a certeza de que a inserção do corpo no Almanaque configura uma proposta de transformação da corporeidade em chave de experiências artísticas e posicionamento político, chave que se opõe ao conservadorismo, na medida em que exibe jovens transitando com longos cabelos, no transe das danças, explorando a particularidade da consciência de seus corpos por meio da arte, e despindo-se na praia de forma despretensiosa para simbolizar uma performance do desfrute da liberdade.

Então, a vivência é representada através deste engajamento na postura da resistência, performada pela exibição do grupo de pessoas realizando as práticas comuns dos espaços, o que remonta a uma observação em que a vida e o cotidiano são parte da arte destes produtores, rompendo com o modelo de divisão entre as atividades artísticas e técnicas (PEREIRA, 1981, p. 59). Nesse âmbito, esta valorização configura um processo de rotinização da arte no esforço de projetá-la em todos os atributos do cotidiano, assim, diluem-se as fronteiras entre os artistas e as obras.

\section{Uma estética transgressora}

A utilização de imagens no Almanaque traz também as experiências promovidas pelo cinema Super- $8^{4}$, que permitia a captura de imagens com um baixo orçamento, resultando em produções de elaboração de forma praticamente artesanal. Estes filmes foram produzidos por Ivan Cardoso, Luiz Otávio Pimentel e o próprio Torquato Neto. No período, eram exibidos nos círculos sociais dos envolvidos. Em Navilouca estamparam-se cartazes e cenas desses filmes e, segundo Ivan Cardoso, “eram de arte e experimentais, com os quais se propunha fazer a fusão das artes

\footnotetext{
${ }^{4}$ Super-8 foi um formato de câmera e película cinematográfica de 8 milímetros $(\mathrm{mm})$ de dimensão, desenvolvidos nos anos 60 pela Kodak para uso doméstico. Nas décadas de 70 e 80 , devido ao seu baixo custo, estes equipamentos foram utilizados para produzir obras independentes com características artísticas, experimentais e de vanguarda.
} 


\section{artigos}

\section{Navilouca - uma experiência do encontro entre arte e vida}

plásticas com o cinema e a fotografia." (CARDOSO; REMIER, 2008, p. 82).

Os filmes produzidos por Ivan Cardoso são uma amostra deste formato. Trazendo novamente a performance do corpo, desta vez, há a adoção de uma estética transgressora, sexualizada e violenta: exibiam mulheres seminuas, facas, armas de fogo e vampiros que desfilam sob o sol carioca. Nestas produções, o estigma da violência se faz presente pela inserção de figuras com o comportamento desviante, entre elas, os mulatos, marginais, homossexuais, jovens de cabelos compridos e a navalha no bolso (RISÉRIO, 2005, p. 29). Essas referências podem ser identificadas nos pôsteres de Nosferato no Brasil (1971) e Chuva de Brotos (1972), elaborados por Luciano Figueiredo. Essas imagens dão ênfase à ideia do cinema de invenção, privilegiando a curiosidade, exploração das imagens, o "faça você mesmo" e as situações cotidianas capturadas sem edição.

Nesses filmes, a realidade se descortina na revelação do estado de agressividade em que vivia a sociedade, privilegiando sujeitos e práticas marginalizadas, funcionando também como agressão às fórmulas do Cinema Novo institucionalizado por Glauber Rocha - cineasta que no período foi duramente criticado pelos organizadores e outros envolvidos em Navilouca, devido ao seu empenho de formalizar a forma de produção do cinema e manifestar-se artisticamente pelos meios compatíveis com a ditadura.

Tais críticas aparecem no texto intitulado "Cruz (câmera)" de Torquato Neto, questionando a fundição das cucas do Cinema Novo com a indústria barra-pesada (a Embrafilme), enquanto ele se aproxima das transas da "marginália" na cidade grande, transas com o novo lixo do curtume nacional. (TORQUATO NETO, 1972 apud. MORICONI, 2016, p. 146). Prática pode ser compreendida por meio da clara intenção 


\section{artigos}

\section{Amanda Costa Ferreira Lucio}

De violentar o público, de entender a arte como um desviante político para figurar o absurdo brasileiro: teatro da crueldade, da agressão e da grossura, da obsessão erótica e até da pornografia; corpo, gesto e teatralidade nos temas e procedimentos tropicalistas, articulando "o conceitual e o fenômeno vivo", como propunha Oiticica, induziam a novas formas de subjetividade. (FAVARETTO, 2019, p. 55).

Essa posição também se evidencia na inserção da foto de uma navalha cortando um prato na quartacapa do impresso. A imagem remete à cena de abertura do filme Nosferato no Brasil (1971), que por sua vez, faz referência ao filme surrealista Un Chien Andalou (1929) de Luiz Buñuel e Salvador Dali. Tal perspectiva é endossada por Torquato Neto ao comentar com Oiticica: "essa revista ficará a coisa mais bonita, mais violenta e mais incrível que você possa imaginar." (NETO, 1972 apud MORICONI, 2017, p. 194).

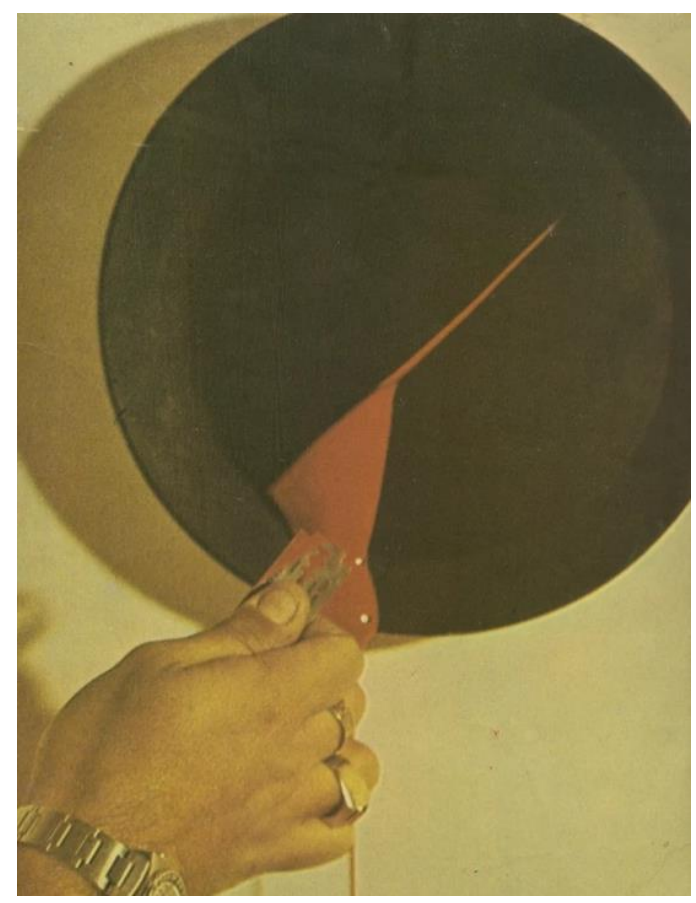

Imagem 4 - Prato sangrando. Navilouca, 1974. Fonte: Torquato Neto, 2018.

O cinema Super-8 - que aquecia a reunião entre os artistas - abria margem para pensar a violência e a agressividade por meio da visualidade. Hélio Oiticica explorador desta temática com frequência - estava em Nova York em 1972, e utiliza 


\section{artigos}

\section{Navilouca - uma experiência do encontro entre arte e vida}

as imagens da cidade grande e violência urbana para ressaltar os sujeitos que não se inserem no fluxo da vida cotidiana comum, pois, sua existência está atrelada às práticas da boemia, bandidagem, sexualidade latente e também da pobreza.

Por exemplo, no espaço-página que traz seus trabalhos, a obra Manhattan (OITICICA, 1974, p. 37) pode ser esquadrinhada por esta lógica: a vivência na metrópole é permeada pelas inquietações sobre as condições de vida naquelas circunstâncias. Na obra, a fotografia em preto e branco ilustra um morador de rua negro dormindo na calçada suja: uma cena que expõe a marginalidade social das cidades grandes, apontando que a existência desses indivíduos, dada as suas condições, figura uma imagem da violência.

\section{O clichê como arte}

A utilização de imagens com significados potentes e que simbolizam práticas cotidianas aparece com recorrência nas páginas do impresso. Ocasionalmente, as imagens estão em conjunto com o texto; outras vezes, sobrepondo-o. Esses jogos, entre imagem e texto, configuram uma prática estética recorrente em Navilouca. Os espaços-página, indicadas pela autoria de Torquato Neto, Waly Sailormoon e Luiz Otávio Pimentel, são marcados pela utilização destes recursos, sobretudo, apresentados em Obras Escolhidas e Nada Sol. Nessas páginas, há uma interseção entre texto e fotografia, trabalhados como colagens: extraindo os objetos de seus contextos para os colocar de forma transitiva, valorizando seus usos no local da origem, recuperando as suas energias criativas (AGUILAR, 2005, p. 149).

A colagem foi um recurso desenvolvido pelo Dadá, e como já indicado, a recuperação dos movimentos de vanguarda do início do século XX foi uma estratégia adotada no Almanaque. Visto que, também permite a utilização desses elementos de 


\section{artigos}

\section{Amanda Costa Ferreira Lucio}

forma não linear, dado que ao retirá-los do seu local comum, expressa uma ruptura com o sentido da temática original. Consistindo em uma prática ready-made empregada por Duchamp e Oswald de Andrade, na qual, o sentido puro da arte era propor o "cartão-postal como arte. O clichê como arte. O problema do kitsch, a chamada pseudo-arte - como a chamou o prof. Anatol Rosenfeld, que inaugurou a questão entre nós. A chamada arte de mau gosto." (PIGNATARI, 1974, p. 164).

Em "Obras escolhidas - Balneário Bahia" (SAILORMOON, 1974, p. 17), é observada a utilização deste recurso, devido à utilização de cartões postais de diferentes áreas de Salvador com inscrições que dialogam com seus significados, na qual "bodas de prata" se inscreve sobre o Elevador Lacerda, "bodas de sangue" no Pelourinho, "bodas de mar" na praia da Aldeia de Arembepe, "bodas de terra" na Cidade Baixa e "bodas de ar" nos coqueiros de Arembepe.

Há um desejo de desmistificar esses lugares, entendido pela recomendação "voe para as praias do norte" e assim experimentar a possibilidade de participar, transitar nestes espaços. Ao lado, há nomes de frutas típicas do nordeste brasileiro e embaixo dos cartões-postais, poemas e trechos com referências a Marx e Foucault, como "18 de Brumário" e "As palavras e as coisas". Com esta prática, Waly atribui um novo sentido ao objeto pronto, as "obras escolhidas" pelo autor propõem o conjunto cartão-postal e poesia como um roteiro de viagem baiano. 


\section{artigos}

\section{Navilouca - uma experiência do encontro entre arte e vida}
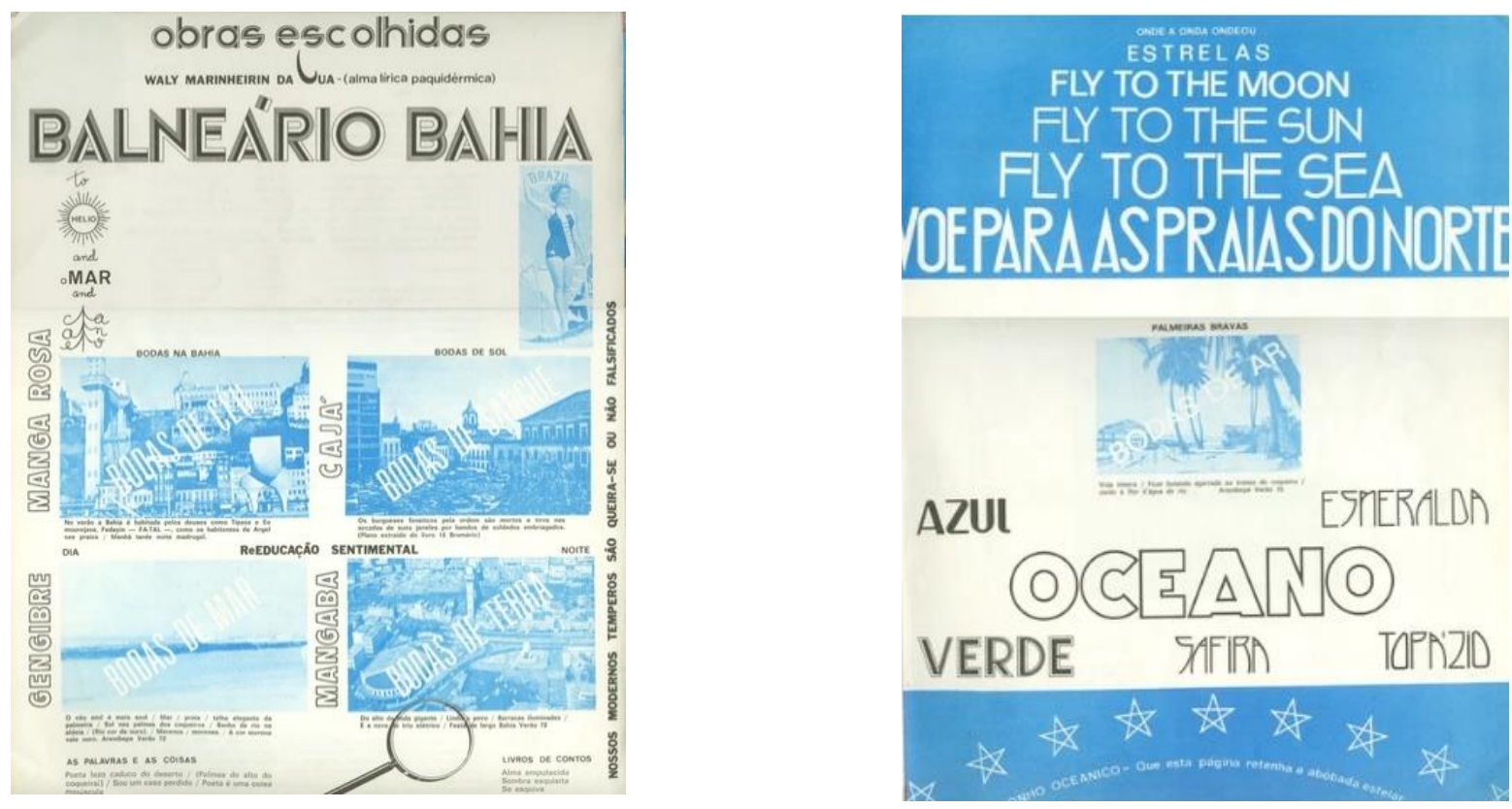

Imagens 5 e 6 - Obras escolhidas. Navilouca, 1974. Fonte: Torquato Neto, 2018.

Ao passo que "Nada Sol", inserida na página indicada por Luiz Otávio Pimentel, é composta por duas fotografias de pessoas assassinadas, em uma região aparentemente periférica, enquanto um grupo de crianças e adultos - possíveis moradores - observam os corpos. Sobre essa imagem está escrito "Nada Sol" de forma desordenada, com inserções de vários pontos rosa-choque em cima das fotografias. Transformando o cotidiano, o clichê - as fotos de homicídios que são comumente divulgadas em jornais populares - em forma de expressão artística. Pimentel remete as cenas de violência da periferia às imagens de terror e marginalidade, problematizando o estado hostil no qual a sociedade daquele período estava inserida, em especial a periferia e a população marginalizada.

O deslocamento do sentido original dos objetos, reformulando suas estruturas, não constituiu uma prática aplicada apenas à fotografia - que evidencia a visualidade -, mas também, por meio da escrita, se identifica a produção de uma nova concepção de arte no Almanaque, destacando a sua composição por uma diversidade de 


\section{artigos}

\section{Amanda Costa Ferreira Lucio}

colaboradores de diversos âmbitos artísticos. Ocasionando uma interpenetração de diversas práticas, nas quais as artes plásticas e gráficas somaram-se a fotografia, filmagens, filmografia, cenografia e performance (DUARTE, 2005, p. 138). Este processo de transmutação das linguagens possibilitou a origem de novos objetos, bem como favoreceu a atribuição de diversos significados aos elementos utilizados, como foi observado no método da colagem.

\section{Considerações finais}

As tensões que marcaram o período do final da década 60 e transcurso para a de 70 , sobretudo, foram enredadas por debates produzidos sobre qual deveria ser o "modo de fazer arte?". No período, a resposta foi caracterizada pela passagem da sensibilidade da arte formal e objetiva para a estetização do cotidiano, atribuindo uma dimensão subjetiva ao processo criativo. Esta "invenção" das formas da arte, publicadas no impresso analisado, permitiu uma observação mais profunda sobre os diversos fragmentos que compunham a Navilouca, em que o comportamento projetava uma produção de sentido para as criações. A singularidade incutida na publicação estava presente desde a reflexão da sua criação, seleção dos trabalhos a serem impressos, estruturação do projeto e a distribuição do material nas páginas impressas.

A mudança da linguagem elaborada ainda nos anos 50, que se baseava no Dadá e nas concepções oswaldianas dos anos 1930 - cujo cerne era atribuir novas significações aos objetos - pode ser identificada nas percepções artísticas de Hélio Oiticica que, por sua vez, fomentou em Navilouca o encontro entre a expansão da arte por meio da incorporação do outro, do espectador, como um elemento construtivo do processo criativo e na adoção de uma postura contracultural respaldada em uma 


\section{artigos}

\section{Navilouca - uma experiência do encontro entre arte e vida}

atitude emancipadora, contestadora e anárquica frente aos formalismos estabelecidos, sejam eles artísticos ou sociais.

Esta interação entre espectador e obra se apresentava de forma indireta em Navilouca, pois, ao tratar-se de um impresso, ficava restrita a participação imediata de quem lê. Entretanto, a inserção do dia-a-dia, do corpo, da vivência dos seus sujeitos e da ressignificação da linguagem poética, ao serem impressas no Almanaque, permitiram a abertura para a concretização da representação da performance cotidiana como incorporação de um novo sentido baseado na invenção, nas instâncias das experiências.

O novo projeto cultural apresentado no Almanaque consistiu na materialização de um espaço que entremeou diversos âmbitos das artes - poesia, fotografia, colagem - construindo um campo aberto para explorar as instâncias da vida em lugar do rigor artístico, caracterizado pelo apego ao enquadramento das formas. Uma concepção que se pautou na descoberta dos elementos do cotidiano, do comportamento humano, transformado por suas próprias leis, por proposições abertas, não-condicionadas (OITICICA, 1986, p. 120). Assim, o discurso do Almanaque indicava uma passagem para um período de espontaneidade artística, exercido, na prática, pelo comportamento, o qual era vivificado por uma geração ávida por mudanças sociais e conquista dos espaços.

Desta forma, pode-se considerar que o corpo não ocupava apenas um lugar figurativo na arte, como se tornava a própria extensão da mesma, capturado através de suas expressões e sentidos em situações que se diluíram entre a performance artística e a realidade. A prática do inesperado, inconsistente, fragmentado estava relacionada a transformação constante da vivência, na qual o gesto espontâneo 


\section{artigos}

Amanda Costa Ferreira Lucio

sobrepunha as determinações estéticas da arte.

A análise do impresso indica apenas um dos caminhos que se entrecruzaram nesta trajetória em busca do deslinde sobre a arte de invenção. Um campo que fomentou intensa participação criativa durante o período estudado, no qual, as possibilidades apontam intensas e variadas produções artísticas que se espraiam em um período que está em constante processo de descoberta, descortinando novos sujeitos e enfoques para a análise das atividades da "marginália" no Brasil.

\section{Fontes}

SALOMÃO, Waly; NETO, Torquato. (Org.). Navilouca. O almanaque dos aqualoucos. Rio de Janeiro: Edições Gernasa, 1974.

\section{Referências Bibliográfica}

AGUILAR, Gonzalo. Poesia concreta brasileira: as vanguardas na encruzilhada modernista. São Paulo: EDUSP, 2005.

ANDRADE, Oswald. "Manifesto da Poesia Pau-Brasil" In: TELES, Gilberto Mendonça. Vanguarda Europeia e Modernismo Brasileiro. Petrópolis: Vozes, 1973, p. 203-208.

BRADBURY, Malcolm, MCFARLANE, James. (org.) Modernismo: guia geral 1890-1930. São Paulo: Companhia das Letras, 1989.

CARDOSO, Ivan; ROCHA, Remier Lion. O mestre do terrir. São Paulo: Imprensaoficial. 2008. 


\section{artigos}

Navilouca - uma experiência do encontro entre arte e vida

CHARTIER, Roger. O mundo como representação. Estudos Avançados. São Paulo, v. 5, n. 11, p. 173-191, abr. 1991. Disponível em <http://www.revistas.usp.br/eav/article/view/8601>. Acesso em 05 fev. 2020.

COELHO, Frederico. Eu, brasileiro, confesso minha culpa e meu pecado. Rio de Janeiro: Editora Civilização Brasileira. 2010.

DUARTE, Paulo Sergio. A arte além da retina. In: In: RISÉRIO, Antonio et al. Anos 70: trajetórias. São Paulo: lluminuras; Itaú Cultural, 2005.

FAVARETTO, Celso. A contracultura, entre a curtição e o experimental. São Paulo: n-1 edições, Coleção Lampejos, v. 1, 2019.

FOUCAULT, Michel. Ditos e Escritos: Estética - literatura e pintura, música e cinema (vol. III). Rio de Janeiro: Forense Universitária, 2001. p. 264-298.

HOLLANDA, H. B. de. Impressões de viagem. CPC, vanguarda e desbunde: 19601970. Rio de Janeiro. Editora Rocco. 1992.

HOBSBAWM, Eric. Era dos Extremos - o breve século XX - 1914-1991. São Paulo: Cia das Letras, 2017.

IMMUB-Instituto Memória Musical Brasileira, 2020. Pesquisas. Disponível em: <https://immub.org/minha-area/Pesquisa>. Acesso em: 10 fev. 2020.

KHOURI, Omar. Revistas na era pós-verso: revistas experimentais e edições autônomas de poemas no Brasil, dos anos 70 aos 90. São Paulo: Ateliê Editorial, 2004.

KUCINSKI, Bernardo. Jornalistas e Revolucionários: nos tempos da imprensa alternativa. São Paulo: Edusp. 2003.

LE GOFF, Jacques. Documento/Monumento. In: História e Memória. Editora da Unicamp: Campinas, 1990.

LEMINSKI, Paulo. "O Veneno das Revistas da Invenção" In: Anseios Crípticos 2. Curitiba: Criar, 2001. 


\section{artigos}

Amanda Costa Ferreira Lucio

LÜSENBRINK, Hans-Jürgen. Do Almanaque Real ao Almanaque de Quebec: representações do poder, representações do Estado, urgências da nação. In: DUTRA, Eliana de Freitas.; MOLLIER, Jean-YVES (org.). Política, nação e edição: o lugar dos impressos na construção da vida política no Brasil, Europa e Américas nos séculos XVIII-XX. São Paulo: Annablume, v.1. 2006.

MORICONI, Italo. Torquato Neto: essencial. Belo Horizonte: Autêntica Editora. 2017.

NETO, Torquato. Os últimos dias de pauperia. Org. Waly Sailormoon. Rio de Janeiro: Editora Eldorado, 1973.

OITICICA, Hélio. Aspiro ao grande labirinto. Rio de Janeiro: Rocco, 1986.

PEREIRA, Carlos Alberto Messeder. Retrato de Época: Poesia marginal anos 70. Rio de Janeiro: Ed. Funarte, 1981.

PIGNATARI, Décio. Contracomunicação. 2.ed. São Paulo: Editora Perspectiva, 1973.

RISÉRIO, Antonio. Duas ou três coisas sobre a Contracultura no Brasil. In: RISÉRIO, Antonio et al. Anos 70: trajetórias. São Paulo: Iluminuras; Itaú Cultural, 2005.

SIRINELLI, Jean-François. Os Intelectuais. In: RÉMOND, René (dir.). Por uma história política. Rio de Janeiro: Editora FGV. 2003.

Imagens

Imagem 1: NAVILOUCA. Capa. 1974. Disponível em: <https://www.ppgav.eba.ufrj.br/publicacao/arte-ensaios-21/>. Acesso em: 27 jan. 2020.

Imagem 2: NAVILOUCA. Alfa Alfavela Alfaville. 1974. Disponível em: <https://www.ppgav.eba.ufrj.br/publicacao/arte-ensaios-21/>. Acesso em: 30 jan. 2020. 


\section{artigos}

Navilouca - uma experiência do encontro entre arte e vida

Imagem 3: NAVILOUCA. Nascer através da dor. 1974. Disponível em: <https://www.torquatoneto.com.br/copia-copia-copia-copia-copia-co-4>. Acesso em: 05 fev. 2020.

Imagem 4: NAVILOUCA. Prato sangrando. 1974. Disponível em: <https://www.torquatoneto.com.br/copia-copia-copia-copia-copia-co-4>. Acesso em: 05 fev. 2020.

Imagens 5 e 6: NAVILOUCA. Obras escolhidas. 1974. Disponível em: <https://www.torquatoneto.com.br/copia-copia-copia-copia-copia-co-4>. Acesso em: 10 fev. 2020. 